\title{
Genetic analysis of treated and untreated phenylketonuria in one family
}

\author{
L A Tyfield, A L Meredith, M J Osborn, R Primavesi, T L Chambers, J B Holton, P S Harper
}

\begin{abstract}
We describe a family in which four subjects in two generations have a disorder of phenylalanine metabolism. Two first cousins had different biochemical presentations in the neonatal period. The older child was thought to have a more severe form of phenylketonuria (PKU), and the younger child a milder form. While carrying out family studies we discovered that their mutual grandfather and his older unmarried brother, both of normal intelligence, had a marked and previously undiagnosed hyperphenylalaninaemia. DNA analysis using RFLP haplotypes has shown that there are four independent mutant PKU alleles in this family which are found on three haplotype patterns. None of the affected family members carries a previously defined mutation at the phenylalanine hydroxylase (PAH) locus and so DNA analysis was not able to explain the apparently different biochemical phenotypes in the affected members of this family.
\end{abstract}

It has been known for some time that there are various disorders of phenylalanine metabolism which arise from a reduction in the activity of the hepatic enzyme phenylalanine hydroxylase (PAH). At its most severe, there is virtually a complete loss in enzyme activity, causing blood phenylalanine concentrations to increase sometimes to levels above $3000 \mu \mathrm{mol} / \mathrm{l}$ and phenylketones to appear in the urine. Historically, this condition has been called 'classical' PKU and, if

Section of Molecular Genetics, Department of Clinical Chemistry, Southmead Hospital, Westbury-on-Trym, Bristol BS10 5NB.

L A Tyfield, M J Osborn, J B Holton

Institute of Medical Genetics, University of Wales College of Medicine, Heath Park, Cardiff CF4 4XN.

L A Tyfield, A L Meredith, P S Harper

Department of Paediatrics, Southmead Hospital, Bristol. R Primavesi, T L Chambers

Correspondence to Dr Tyfield.

Received for publication 22 February 1990.

Revised version accepted for publication 12 April 1990. not treated with a low phenylalanine diet from very early in life, will result in severe and irreversible mental retardation.

In milder forms of the disorder, the biochemical picture at presentation is less dramatic because there is only a reduction in the activity of the enzyme. ${ }^{1}$ Blood phenylalanine concentrations can range between 240 and $1200 \mu \mathrm{mol} / 1$ and phenylketones are not always found in the urine. This condition is called persistent hyperphenylalaninaemia (HPA) and in its mildest form, when blood phenylalanine concentrations are less than $430 \mu \mathrm{mol} / \mathrm{l}$, no dietary phenylalanine restriction is required. However, other infants have a more reduced capacity to metabolise phenylalanine and some phenylalanine restriction may be desirable, particularly in early infancy to ensure that blood phenylalanine concentrations do not rise to levels which would impair normal brain development. ${ }^{2}$ ?

The availability of a probe for the phenylalanine hydroxylase locus ${ }^{3}$ has increased the understanding of the molecular genetics of PKU. Various haplotypes can be constructed from the eight restriction fragment length polymorphisms (RFLPs) associated with the PAH locus, but in most populations the mutant gene is usually associated with only four of these, numbered simply 1 to $4 .^{4-11}$ The correlation between differences in biochemical expression and the various haplotype patterns was first noted by Guttler et $a l^{12}$ and since then several specific mutations in linkage disequilibrium with various haplotypes have been defined. ${ }^{13-18}$

We report a family in which there are four affected subjects in two generations. One child, born in 1972, was thought to have 'classical PKU' and her cousin, born in 1987, is known to have a milder form of the disorder. Both were diagnosed in the neonatal period. Their mutual grandfather, born in 1925, and his older unmarried brother also have significant hyperphenylalaninaemia which had been previously undiagnosed. The purpose of the study was to see if RFLP haplotype data and the analysis of specific mutations might explain the apparent differences in biochemical phenotype in this family.

\section{Methods}

RFLP ANALYSIS AND HAPLOTYPE DETERMINATION

Leucocyte DNA from each family member was 
digested with seven restriction enzymes: $B g l \mathrm{II}, P v u \mathrm{II}$, EcoRI, MspI, XmnI, HindIII, and EcoRV. ${ }^{19}$ PvuII and $M s p I$ each highlight two polymorphic sites. Agarose gel electrophoresis and transfer of DNA fragments to a nylon membrane (Hybond $\mathrm{N}$, Amersham) were carried out using standard protocols. ${ }^{20}$ Filters were hybridised overnight at $65^{\circ} \mathrm{C}$ with the cDNA probe PAH247 (kindly supplied by Dr Savio Woo, Houston, Texas) which had been radiolabelled with ${ }^{32} \mathrm{P}$ according to the method of Feinberg and Vogelstein. ${ }^{21}$ Filters were washed at $65^{\circ} \mathrm{C}$ for 15 minutes each with $2 \times$ SSC and $1 \times$ SSC.

\section{TESTING FOR SPECIFIC MUTATIONS}

Specific exons were amplified in a Perkin Elmer Cetus Thermocycler using exon specific primers ${ }^{22}$ and AmpliTaq (Perkin Elmer). After purification, the amplified products were spotted onto Hybond $\mathrm{N}$ (Amersham) and hybridised with radiolabelled allele specific oligonucleotide (ASO) probes ${ }^{13}{ }^{14}$ according to standard protocols. Primer sequences for amplifying exons 7 and 5 to test for the arginine to glutamine replacements associated with haplotypes 1 and 4 respectively ${ }^{17}$ were determined from DiLella et al. ${ }^{3}$ Sequences for the normal and mutant ASO probes were determined from Kwok et al. ${ }^{23}$ Positive controls (kindly supplied by E Kunert, Leipzig, GDR, for the exon 5 and 7 mutations) were included in all hybridisations.

\section{DETERMINATION OF BLOOD PHENYLALANINE} CONCENTRATIONS

Capillary blood was collected onto filter paper and the phenylalanine concentration measured by a fluorometric assay. Plasma phenylalanine and tyrosine concentrations were measured by column chromatography.

\section{Results}

\section{FAMILY HISTORY}

A concise family pedigree showing the relationship between affected subjects is given in fig 1 .

III. 1 was born in 1972 and at 7 days of age her blood phenylalanine concentration was $580 \mu \mathrm{mol} / \mathrm{l}$. This had increased to $2500 \mu \mathrm{mol} / \mathrm{l}$ at 15 days but phenylketones were not reported in the urine. For the first 18 months of her life, her phenylalanine intake was 40 to $50 \mathrm{mg} / \mathrm{kg} / \mathrm{day}$ and her blood phenylalanine concentration was generally between 60 and 240 $\mu \mathrm{mol} / \mathrm{l}$. At 12 months of age she was challenged with cow's milk for a few days (between 85 and $115 \mathrm{mg}$ phenylalanine $/ \mathrm{kg} /$ day) and her blood phenylalanine concentration rose from 240 to $1800 \mu \mathrm{mol} / \mathrm{l}$ after 60 hours. It was believed that this confirmed a diagnosis

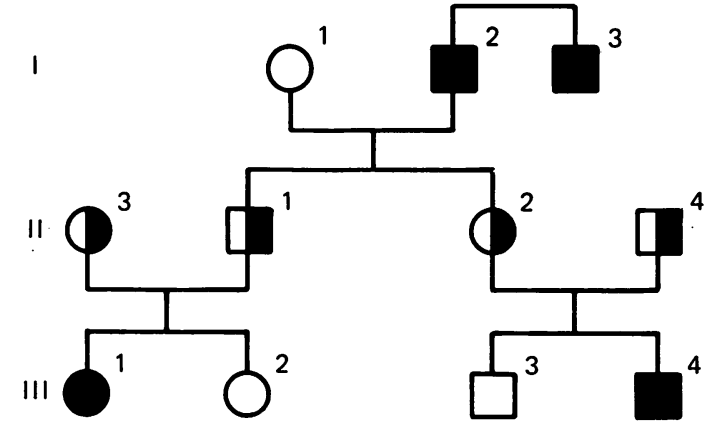

Figure 1 Family pedigree. Filled circles or squares are homozygous affected subjects and half filled circles or squares are obligate heterozygotes. I.1 and I.3 died during the course of the study.

of 'classical' PKU. Until the age of 16 years she had a restricted phenylalanine intake. This varied from 44 to $50 \mathrm{mg} / \mathrm{kg} /$ day but there was doubt about her compliance particularly in late childhood. Up to the age of 10 years her blood phenylalanine concentrations were generally between 350 and $550 \mu \mathrm{mol} / \mathrm{l}$. Between 10 and 16 years they were between 650 and $900 \mu \mathrm{mol} / \mathrm{l}$. Her physical and mental development are normal (at 12 years: verbal IQ 95, performance IQ 104 , reading skills, accuracy score, Neal test 10 years 8 months, comprehensive score 12 years).

III.4, born in 1987, has a mild form of the condition. At 8 days of age his blood spot phenylalanine result was $350 \mu \mathrm{mol} / 1$ and this increased to 650 at 34 days of age when some dietary phenylalanine restriction was started. For his first year of life his phenylalanine intake was $75 \mathrm{mg} / \mathrm{kg} / \mathrm{day}$ and his blood phenylalanine concentration during this time was consistently between 300 and $500 \mu \mathrm{mol} / \mathrm{l}$. From two years of age he has been allowed an unrestricted dietary intake and his blood phenylalanine concentrations have been between 450 and $750 \mu \mathrm{mol} / \mathrm{l}$. His physical and mental development are normal.

I. 2 and I. 3 were born in 1925 and 1923, respectively. Initially I. 2 was studied biochemically and genetically to determine which grandparent was a carrier of the mutant PKU gene. He was found to have a significant hyperphenylalaninaemia which had not been previously diagnosed. His fasting midday phenylalanine concentration was $1020 \mu \mathrm{mol} / \mathrm{l}$ and the tyrosine was 73 $\mu \mathrm{mol} / \mathrm{l}$. His older unmarried brother, I.3, had a random blood spot phenylalanine concentration of $860 \mu \mathrm{mol} / \mathrm{l}$. Both men are apparently of normal intelligence. I. 2 had held desk jobs requiring numerical skills in his working life.

INHERITANCE OF HAPLOTYPES AT THE PAH LOCUS

Fig 2 summarises the inheritance of the haplotypes at 


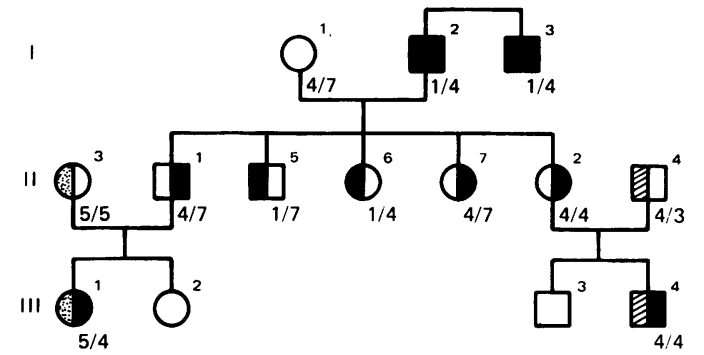

Figure 2 Showing the inheritance of mutant alleles from the grandfather. Symbols blackened on the left are carriers of the mutant haplotype 1 alleles; symbols blackened on the right are carriers of mutant haplotype 4 alleles inherited from the grandfather. Symbols shaded on the left indicate carriers of the mutant haplotype 5 allele; symbols hatched on the left indicate carriers of a second mutant haplotype 4 allele.

the phenylalanine hydroxylase locus in the complete family. Haplotype numbers are the same as those used by Chakraborty et al. ${ }^{4}$ RFLP analysis has shown that in this family there may be as many as four independent PKU mutations associated with three different haplotype patterns. The children are genetically different from each other and from their grandfather because they all have different combinations of haplotype patterns at the PAH locus. However, they all have one mutant haplotype 4 allele in common and gene tracking has shown that the affected children inherited this mutant gene from their grandfather via their parents who are brother and sister (II.1 and II.2). Gene tracking using RFLP haplotype patterns has also shown that II.7 inherited the mutant haplotype 4 allele from her father (I.2) and that II.5 and II.6 inherited the mutant haplotype 1 allele.

\section{SPECIFIC POINT MUTATIONS}

Amplification of exons 5, 7, and 12 and hybridisation of dot blots with allele specific oligonucleotide probes showed that none of the affected subjects in this family carried any of the mutations associated with haplotypes $1,2,3$, and 4 in other populations. In addition, the exon 9 mutation found on haplotype 10 in two German families ${ }^{15}$ does not occur in this family, for an altered $M s p I$ site was not observed.

\section{BIOCHEMICAL RESULTS}

The fasting midday phenylalanine/tyrosine ratios (fig 3) confirmed carrier status in the parents of the children although it was interesting to note that only the father of the child with the milder form of the disorder had a result well into the heterozygote range, all others being just within the range of probability that they carry a mutant allele. II.6 had a random

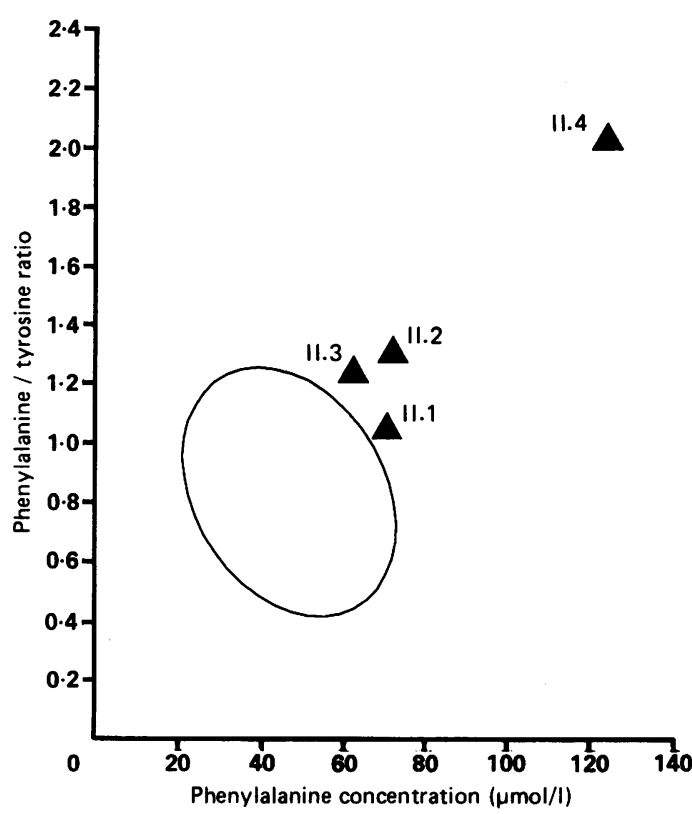

Figure 3 Showing the fasting midday phenylalanine/tyrosine ratios of the obligate heterozygotes in generation II (from Scriver and Rosenberg $\left.{ }^{24}\right)$. The ellipse is the contour of probability that values inside indicate the homozygous normal phenotype.

blood spot phenylalanine concentration of $135 \mu \mathrm{mol} / \mathrm{i}$ which was within the adult reference range. ${ }^{25}$

\section{Discussion}

Molecular cloning of the phenylalanine hydroxylase gene and the identification of specific mutations within the gene has allowed direct analysis of this locus in the various types of hyperphenylalaninaemia. In all populations studied, the majority of mutant alleles has occurred on just four haplotypes, numbered 1 to 4. Specific mutations in linkage disequilibrium with haplotypes 2 and 3 in the Danish population have been defined, a point mutation at exon 12 occurring on haplotype $2^{14}$ and a splice mutation at the intron/exon junction of exon 12 occurring on haplotype $3 .^{13}$ Both mutations lead to a complete loss of enzyme activity and so in the Danish study patients who had any combination of mutant haplotype 2 and 3 invariably had a more severe form of the disorder. ${ }^{12}$ The tight linkage between haplotype 3 and the splicing mutation has also been found in other populations ${ }^{6726}$; however, with each of the other common haplotypes more than one mutation can account for a reduction in or absence of enzyme activity. In the Swiss population, for example, the specific mutations defined in exons 7 and 5 were found on only $72 \%$ and $33 \%$ of mutant haplotype 1 
and 4 alleles respectively, ${ }^{\prime \prime}$ and in PKU patients in the south west of England, ${ }^{26}$ the point mutation in exon 12 was found on both haplotype 1 and 2 mutant alleles.

In the family reported here, there are four subjects in two generations who have compromised phenylalanine metabolism. Although there may be as many as four independent mutations on three different haplotype patterns in this family, none of the mutant alleles carries any of the mutations already defined (unpublished observations). III.1, in particular, who is believed to have a more severe form of the disorder has neither of the exon 12 mutations which results in a complete loss in enzyme activity. This was not unexpected since she did not have a haplotype 2 or 3 mutant allele and to date haplotype 5 has no associated point mutation. It can only be concluded that all of the mutant alleles in this family associated with haplotypes 1,4 , and 5 carry mutations which have not yet been defined and so genetic analysis alone has not been able to explain the apparent differences in biochemical phenotype.

Biochemical tests are available for discriminating between PKU and HPA and these range from oral or intravenous load tests ${ }^{27}$ to evaluating the activity of the enzyme in vitro after a liver biopsy ${ }^{28}$ or in vivo using labelled substrate and measuring the formation of labelled products. ${ }^{29}$ These tests are highly invasive or require sophisticated laboratory equipment and none has been carried out on affected subjects in the family reported here.

Because the two children were diagnosed in the neonatal period, both have been treated with a restricted phenylalanine intake in early infancy and childhood and their mental development has not been impaired. Regarding the two older men, however, it is curious that they are of apparently normal intelligence despite the fact that their blood phenylalanine concentrations are in a range that would normally be associated with some degree of mental impairment. Undoubtedly they carry a mutation of a less deleterious kind on one of their mutant alleles, but, in addition, one could speculate that their blood phenylalanine levels were lower in infancy and early childhood than they are now in their seventh decade of life. This could have arisen either because their dietary phenylalanine intake was unknowingly restricted at a critical period of brain development or because their hydroxylating systems have become less efficient with age. Scriver et $a l^{25}$ reported that normal plasma phenylalanine values in young and adult subjects are similar to those in the neonatal period; however, in persons in whom the hydroxylating system is already considerably compromised, it is possible that it becomes less efficient with advancing age. Only regular blood sampling over many years of those subjects with persistent, mild hyperphenylalaninaemia would provide an answer.
Clearly, this becomes an important consideration in relation to females who have had mild persistent hyperphenylalaninaemia since the neonatal period but in whom dietary phenylalanine restriction was not considered necessary to ensure their own normal brain development. If their blood phenylalanine concentration can increase with age, it may become sufficiently high in their third or fourth decade of life to affect adversely the development of a fetus and thereby result in an infant being born with the syndrome of maternal PKU. Regular monitoring of blood phenylalanine concentrations of even the mildest forms of PKU in females should be considered essential.

MJO was supported by a grant from the South Western Regional Health Authority. We are grateful to $\operatorname{Dr}$ E Kunert, Leipzig, for making available positive controls for the exon 5 and 7 mutations and to Mr Paul Rutland, London, for the normal haplotype 4 ASO probe.

1 Lehmann WD. Progress in the identification of the heterozygote in phenylketonuria. $f$ Pediatr 1989;114:915-24.

2 ScriverCR, Kaufman S, Woo SLC. The hyperphenylalaninaemias. In: Scriver CR, Beaudet AL, Sly WS, Valle D, eds. The metabolic basis of inherited disease. 6th ed, vol I. New York: McGrawHill, 1989:495-546.

3 DiLella AG, Kwok SCM, Ledley FD, Marvit J, Woo SLC. Molecular structure and polymorphic map of the human phenylalanine hydroxylase gene. Biochemistry 1986;25:743-9.

4 Chakraborty R, Lidsky AS, Daiger SP, et al. Polymorphic DNA haplotypes at the human phenylalanine hydroxylase locus and their relationship with phenylketonuria. Hum Genet 1987;76: $40-6$.

5 Aulchla-Scholz C, Vorgerd M, Sautter E, et al. Phenylketonuria: distribution of DNA diagnostic patterns in German families. Hum Genet 1988;78:353-5.

6 Lichter-Konecki U, Schlotter M, Konecki DS, Labeit S, Woo SLC, Trefz FK. Linkage disequilibrium between mutation and RFLP haplotype at the phenylalanine hydroxylase locus in the German population. Hum Genet 1988;78:347-52.

7 Rey F, Berthelon M, Caillaud C, et al. Clinical and molecular heterogeneity of phenylalanine hydroxylase deficiencies in France. Am f Hum Genet 1988;43:914-21.

8 Tyfield LA, Meredith AL, Osborn MJ, Harper PS. Identification of the haplotype pattern associated with the mutant PKU allele in the Gypsy population of Wales. $\mathcal{F}$ Med Genet 1989;26: $499-503$.

9 Hertzberg M, Jahroni K, Ferguson V, et al. Phenylalanine hydroxylase gene haplotypes in Polynesians. Evolutionary origins and absence of alleles associated with severe phenylketonuria. Am f Hum Genet 1989;44:382-7.

10 Sullivan SE, Moore SD, Connor JM, et al. Haplotype distribution of the human phenylalanine hydroxylase locus in Scotland and Switzerland. Am 7 Hum Genet 1989;44:652-9.

11 Reiss O, Michel A, Speer A, Meiske W, Cobet G, Coutelle C. Linkage disequilibrium between RFLP haplotype 2 and the affected PAH allele in PKU families from the Berlin area of the German Democratic Republic. Hum Genet 1988;78:343-6.

12 Guttler F, Ledley FD, Lidsky AS, DiLella AG, Sullivan SE, Woo SLC. Correlation between polymorphic DNA haplotypes at phenylalanine hydroxylase locus and clinical phenotypes of phenylketonuria. $\mathcal{F}$ Pediatr 1987;110:68-71.

13 DiLella AG, Marvit J, Lidsky AS, Guttler F, Woo SLC. Tight linkage between a splicing mutation and a specific DNA haplotype in phenylketonuria. Nature 1986;322:799-803.

14 DiLella AG, Marvit J, Brayton K, Woo SLC. An amino-acid substitution involved in phenylketonuria is in linkage disequilibrium with DNA haplotype 2. Nature 1987;327:333-6.

15 Lichter-Konecki U, Konecki D, DiLella AG, et al. Phenylalanine hydroxylase deficiency caused by a single base substitution in an exon of the human phenylalanine hydroxylase gene. Biochemistry 1988;27:2881-5. 
16 Lyonnet S, Caillaud C, Rey F, et al. Molecular genetics of phenylketonuria in Mediterranean countries: a mutation associated with partial phenylalanine hydroxylase activity. $A m \mathcal{F}$ Hum Genet 1989;44:511-7.

17 Okano Y, Wang T, Eisensmith RC, Steinmann B, Gitzelmann R, Woo SLC. Mis-sense mutation associated with RFLP haplotypes 1 and 4 of the human phenylalanine hydroxylase gene. Am 7 Hum Genet 1990;46:18-25.

18 Avigad S, Cohen BE, Woo SLC, Shiloh Y. A specific deletion within the phenylalanine hydroxylase gene is common to most Yemenite Jewish phenylketonuric patients. Am $\mathcal{F}$ Hum Genet 1987;41:205A.

19 Lidsky AS, Ledley FD, DiLella AG, et al. Extensive restriction site polymorphism at the human phenylalanine hydroxylase locus and application in prenatal diagnosis of phenylketonuria. Am F Hum Genet 1985;37:629-34.

20 Southern EM. Detection of specific sequences among DNA fragments separated by gel electrophoresis. $\mathcal{F ~ M o l ~ B i o l ~ 1 9 7 5 ; 9 8 : ~}$ 503-17.

21 Feinberg AP, Vogelstein B. A technique for radiolabelling DNA restriction endonuclease fragments to high specific activity. Anal Biochem 1983;132:6-13.

22 DiLella AG, Huang WM, Woo SLC. Screening for phenylketonuria mutations by DNA amplification with the polymerase chain reaction. Lancet 1988;i:497-9.
23 Kwok SCM, Ledley FD, DiLella AG, Robson KJH, Woo SLC. Nucleotide sequence of a full-length complementary DNA clone and amino acid sequence of human phenylalanine hydroxylase. Biochemistry 1985;24:556-61.

24 Scriver CR, Rosenberg LE. Phenylalanine. In: Amino acid metabolism and its disorders. Major Problems in Clinical Paediatrics Vol X. Philadelphia: Saunders, 1973:320.

25 Scriver CR, Gregory DM, Sovatts D, Tissenbaum G. Normal plasma free amino acid values in adults: the influence of some common physiological variables. Metabolism 1985;34:868-73.

26 Tyfield LA, Kunert E, Osborn MJ, Rutland P. PKU in South Western England and in the South of the German Democratic Republic: genetic heterogeneity in two populations. Abstract. Clinical Genetics Society/Clinical Molecular Genetics Society Joint Meeting, April 1990. 7 Med Genet (in press).

27 Blitzer MG, Bailey-Wilson JE, Shapira E. Discrimination of phenylketonurics from persistent hyperphenylalaninaemia patients using a simple phenylalanine loading test. Clin Chim Acta 1985;153:137-42.

28 Berry HK, Hsiah MH, Bofinger MK, Shubert WK. Diagnosis of phenylalanine hydroxylase deficiency (phenylketonuria). $A m \mathcal{F}$ Dis Child 1982;136:111-4.

29 Trefz FK, Bartholome H, Bickel H, Lutz P, Schmidt H, Seyberth HW. In vivo residual activities of the phenylalanine hydroxylating system in phenylketonuria and variants. 7 Inher Metab Dis 1981;4:101-3. 